\title{
LAÇOS DE SOLIDARIEDADE: \\ FAMÍLIA E PARENTESCO ENTRE OS AFRODESCENDENTES DO MUNICÍPIO DE JUIZ DE FORA NO PÓS-EMANCIPAÇÃO
}

LAZOS DE SOLIDARIDAD:

FAMILIA Y PARENTESCO ENTRE LOS AFRODESCENDIENTES DEL MUNICIPIO DE JUIZ DE FORA TRAS LA EMANCIPACIÓN

SOLIDARITY TIES:

POST-EMANCIPATION FAMILIES AND RELATIVES AMONG THE MUNICIPALITY OF JUIZ DE FORA'S POPULATION OF AFRICAN DESCENT

\section{LIENS DE SOLIDARITÉ: \\ FAMILLE ET PARENTÉ PARMI LES AFRODESCENDANTS DE LA COMMUNE DE JUIZ DE FORA APRÈS L'ÉMANCIPATION}

DOI: $10.5533 / 1984-2503-20124203$

Raquel Pereira Francisco ${ }^{1}$

\section{RESUMO}

O trabalho analisa as relações familiares e de parentesco, consanguíneo e ritual, na população afrodescendente do município cafeicultor de Juiz de Fora no pós-emancipação. $\mathrm{O}$ artigo procura demonstrar por meio dos registros de casamentos, nascimentos e dos assentos de batismo a importância dada a esses laços pelos libertos, que procuraram no pós-abolição o reconhecimento legal de suas uniões e de seus filhos.

Palavras-chave: família; parentesco; casamento; batismo; pós-abolição.

\section{RESUMEN}

El trabajo analiza las relaciones familiares y de parentesco, consanguineo y ritual, entre la población afrodescendiente del municipio cafeicultor de Juiz de Fora tras la emancipación. El artículo busca demostrar por medio de los registros de casamientos, nacimientos y de los asientos de bautismo la importancia dada a estos lazos por los libertos, que buscaron después de la emancipación el reconocimiento legal de sus uniones y de sus hijos.

Palabras-clave: família; parentesco; casamento; bautismo; post-abolición.

\footnotetext{
${ }^{1}$ Doutoranda do Programa de Pós-Graduação em História da Universidade Federal Fluminense. E-mail: raquel franc@yahoo.com.br
} 


\section{ABSTRACT}

This work analyses post-emancipation relations between families and relatives, both consanguine and affinal, among the population of African descent in the coffee-growing municipality of Juiz de Fora. The articles seeks to demonstrate, by means of records on marriage, birth and baptism, the importance given to these ties by the emancipated slaves, who sought post-abolition legal recognition of their unions and those of their children.

Key words: family; relationship; marriage; baptism; post abolition.

\section{RÉSUMÉ}

Ce travail analyse les rapports familiaux et de parenté, consanguins et rituels, parmi la population d'origine africaine de la commune caféicultrice de Juiz de Fora suite à l'abolition de l'esclavage. L'objectif est ici de démontrer, grâce aux registres de mariage, de naissance et de baptême, l'importance donnée à ces liens par les esclaves nouvellement libérés, qui cherchèrent après l'abolition la reconnaissance légale de leurs unions et de leurs enfants.

Mots-clés : famille; parenté ; mariage ; baptême ; post-abolition.

O pós-abolição na sociedade brasileira é um tema que está sendo revolvido pelos pesquisadores há algum tempo, com o objetivo de se reconstruir as várias vivências dos libertos do pós 13 de maio de $1888^{2}$. Nesse intuito, as entrevistas com descendentes dos últimos escravos ${ }^{3}$ tem sido de fundamental importância para se compreender o que esses homens e mulheres egressos do cativeiro entendiam por liberdade, o que esperavam da liberdade e quais eram os seus projetos de vida depois que o "sol da liberdade" raiou. As entrevistas, a análise das fontes com um novo olhar, a leitura nas entrelinhas dos documentos e a adoção de novos referenciais teóricos e metodológicos pelos estudiosos, tem feito emergir outras visões sobre o pós-emancipação.

\footnotetext{
${ }^{2}$ Este artigo é parte do capítulo 5 de minha dissertação de mestrado: Francisco, Raquel Pereira. (2007). Laços da senzala, arranjos da flor de maio: relações familiares e de parentesco entre a população escrava $e$ liberta - Juiz de Fora (1870-1900), Niterói: Programa de Pós-Graduação em História da Universidade Federal Fluminense (Orientação: Sheila de Castro Faria)..

${ }^{3}$ Segundo Stuart Schwartz nos Estados Unidos a coleta de relatos de ex-escravos iniciou-se nas primeiras décadas do século XX. No Brasil, pelo contrário, a iniciativa mais sistemática de se recolher relatos de pessoas que viveram o cativeiro deu-se já no final do século $X X$ quando a grande maioria dos que foram escravos já estavam mortos. Devido a esse fator, as recordações dos últimos escravos do Brasil são colhidas através das falas de seus filhos e netos. Schwartz, Stuart. "Prefácio". In Rios, Ana Maria Lugão; Mattos, Hebe Maria (2005). Memórias do cativeiro: família, trabalho e cidadania no pós-emancipação, Rio de Janeiro: Civilização Brasileira, p. 8-9.
} 
São relativamente recentes os estudos que buscam resgatar as vivencias dos libertos depois da abolição da escravidão no Brasil. A literatura sobre o destino dos últimos escravos e seus descendentes até a década de 1990, aproximadamente, preocuparam-se basicamente apenas com a sua marginalização, a sua não integração na sociedade de classe. É como se não houvesse mais nada a que se examinar sobre os homens egressos do cativeiro a não ser a sua exclusão na nova ordem social que surgiu após o fim do cativeiro. Segundo Ana Rios e Hebe Mattos, a impressão que se tem é que com a abolição da escravidão os cativos parecem "ter saído das senzalas e da história, substituídos pela chegada em massa de imigrantes europeus"4. Os estudos, que abordam o período pós-cativeiro, preocuparam-se mais em discutir sobre a problemática da formação do povo brasileiro e com a questão social, do que com o viver dos libertos ${ }^{5}$.

Os trabalhos desenvolvidos durante a década de 1970 sobre o Caribe britânico procuraram observar a especificidade dos processos emancipacionistas. ${ }^{6}$ As abordagens que foram tecidas sobre abolição na Jamaica e em Trinidad relacionaram 0 comportamento dos libertos a questão da fronteira agrícola (aberta ou fechada). Em áreas em que a fronteira estava aberta os ex-escravos buscaram um modo de vida autônomo, e em uma situação inversa o recurso foi a sujeição às condições propostas pelos patrões.

Algumas abordagens desenvolvidas no Brasil nas décadas de 1970 e 1980 seguiram esse viés interpretativo. Entretanto, Ana Rios e Hebe Mattos refletem que a realidade não é tão simples quanto parece e a questão da fronteira agrícola por si só não explica toda a complexa trama do pós-abolição. Segundo as autoras, estudos mais pormenorizados sobre a Jamaica demonstraram que a existência da fronteira aberta não foi o fator preponderante para a constituição camponesa. A formação das vilas camponesas na Jamaica foi palco de acirradas lutas e embates travados pelos libertos. Dentro deste contexto a historiografia brasileira, principalmente nos anos 1990, também passou a investigar a questão de um "projeto camponês" entre os libertos do pós 13 de maio, para além da questão da existência ou não de uma fronteira aberta ${ }^{7}$.

Os estudos têm levado em conta as especificidades regionais, as leis do país com relação ao acesso a terra, as diferenças de significados de liberdade para ex-escravos do

\footnotetext{
${ }^{4}$ Rios, Ana Maria; Mattos, Hebe Maria (2004). "O pós-abolição como problema histórico: balanço e perspectivas". In Topoi, v. 5, n. 8, jan.jun., p. 170. www.ppghis.ifcs.ufri.br/media/topoi8a5.pdf

${ }^{5}$ Ibidem.

6 Para mais informações sobre o processo emancipacionista das colônias britânicas ver entre outros Holt, Thomas C. (2005). "A essência do contrato: a articulação entre raça, gênero sexual e economia política no programa britânico de emancipação, 1838-1866". In Cooper, Frederick et. All. (2005). Além da escravidão: investigação sobre raça, trabalho e cidadania em sociedades pós-emancipação, Rio de Janeiro: Civilização Brasileira.

${ }^{7}$ Rios; Mattos (2004). Op. cit., p. 171-173.
} 
meio rural e urbano, entre os que tinham uma inserção maior no mundo dos livres e os que não tinham etc. Apesar dos projetos e expectativas dos libertos apresentarem nuanças diferentes devido aos fatores assinalados, muitos traços semelhantes são perceptíveis entre os ex-escravos das Américas, como a busca por mais autonomia e controle sobre os ritmos e tempo de trabalho, a retirada das mulheres e crianças do trabalho em grupo, e supervisionado no "eito", e a todas as atitudes e práticas que os lembrassem da escravidão como a restrição do direito de ir e vir, os castigos, as refeições em grupo etc. ${ }^{8}$.

Outra característica comum aos processos emancipacionistas nas Américas é o desejo que os libertos tinham de reunir os familiares que foram separados durante 0 período escravista. É a busca pela (re)construção de laços familiares e de parentesco pelos libertos no pós-abolição no município de Juiz de Fora, que pretendo abordar neste artigo. Como Eric Foner assinalou, a maioria dos libertos tinha ânsia de reunir os parentes que foram separados durante a escravidão. Para que tal intuito fosse atingido, eles recorreram a vários meios como publicações em jornais procurando seus entes queridos, a locomoção de uma região para outra etc. ${ }^{9}$ Em Juiz de Fora esse desejo por reencontrar os parentes apartados durante a escravidão pode ser percebido em uma notícia publicada no jornal $O$ Pharol em novembro de 1888 em que a ex-escravizada Felicidade procurava saber onde se encontravam as suas irmãs, Ephygenia e Cathariana. As informações que possuía é a de que elas estariam provavelmente em Ubá, Leopoldina ou Cataguases (cidades próximas de Juiz de Fora e localizadas na Zona da Mata mineira) e que Ephygenia tinha sido escrava de José Izidoro. ${ }^{10} \mathrm{O}$ desejo de reunir os familiares, de legalizar uniões pode ser visualizado através do número expressivo de casamentos após a abolição. Os "casamentos em massa" de ex-escravos após a decretação da áurea lei de 13 de maio é um indício da importância que os libertos davam as suas relações familiares ${ }^{11}$.

Investigar os caminhos trilhados pelos libertos após a abolição nem sempre é uma tarefa fácil devido ao relativo sumiço das "marcas da escravidão" em muitos documentos. Em vários registros do pós-abolição os egressos do cativeiro não vem acompanhados de informações como cor, condição (liberto, ex-escravo, foi escravo de fulano), origem (angolano, congo, cabinda, crioulo...), comuns nas fontes do período anterior. Apesar das

\footnotetext{
${ }^{8}$ Ibidem, p. 174.

${ }^{9}$ Foner, Eric (1988b). "O significado da liberdade". In Lara, Silvia Hunold (org.) (1988). Escravidão. Revista Brasileira de História, São Paulo: ANPUH/Marco Zero, vol. 8, n. 16, mar/ag., p. 16.

${ }_{10}$ BMMM-SM: O Pharol, quarta feira, 07/11/1888, p. 2.

${ }^{11}$ Rios; Mattos (2004). Op. cit., p. 186.
} 
dificuldades, os estudos têm avançado. Muitas vezes, para se acompanhar a trajetória desses homens, é necessário ir costurando informações de vários processos, comparar nomes, local de residência, datas de nascimento, casamento, óbito (nos registros eclesiásticos e civis) etc. Além dos registros escritos, os pesquisadores ainda podem recorrer aos relatos dos descendentes dos últimos escravos do Brasil escravista.

O registro civil foi instituído no Brasil em 1888 e uma das informações que deveria conter era a cor das pessoas. Entretanto, esse quesito nem sempre esteve presente na documentação. ${ }^{12}$ Nos registros civis de casamento do distrito de São Francisco de Paula, por mim analisados, dados como a cor, idade, condição, naturalidade, profissão, filiação, a data da celebração religiosa, se tivesse acontecido, foram anotadas sistematicamente até meados do ano de 1890. A partir de então, todas essas informações tão preciosas para o historiador vão desaparecendo dos livros. Os dados tornam-se sucintos, a menção do rito religioso desaparece, a cor e condição não são mais tão presentes. ${ }^{13}$ Para Ana Rios e Hebe Mattos, o ano de 1889 é especial para os estudiosos que trabalham com registro civil. As incertezas de como deveria ser a redação do mesmo levou os escrivães a registrarem todas as informações dos declarantes. A grande procura dos libertos para registrar e documentar suas relações familiares, logo após a abolição, pode ser interpretado como uma maneira encontrada pelos mesmos de terem seus laços familiares reconhecidos pela sociedade. ${ }^{14}$ Essa vontade de legalizar as uniões também foi percebida por Eric Foner com relação aos libertos dos Estados Unidos ${ }^{15}$.

Nos assentos eclesiásticos de matrimônio e batismo do pós-abolição, paulatinamente a cor e condição dos envolvidos também foram deixando de ser anotados. A falta de sobrenome ${ }^{16}$ é bem comum na documentação produzida pela Igreja Católica (batismo e casamento) de Juiz de Fora e à primeira vista pode sugerir a existência de um passado escravo, devido ao fato da adoção de sobrenome não ser comum entre a população cativa do Brasil. Mas trabalhar com tais dados pode nos levar a incorrer em erros e equívocos, pois entre os sem sobrenome pode estar os homens livres pobres e até mesmo imigrantes. Coletei 277 registros nos livros de batizados da Catedral Metropolitana de Juiz de Fora entre os anos de 1888 a 1900, em que as pessoas

\footnotetext{
${ }^{12}$ Ibidem, p. 176.

${ }^{13}$ AHCJF: Livros de Registro Civil de Casamento - São Francisco de Paula. A mudança na realização dos registros a partir do ano de 1890 foi bem perceptível nos livros de casamento da freguesia de São Francisco de Paula.

${ }^{14}$ Rios; Mattos (2004). Op. cit., p. 186.

${ }^{15}$ Foner, Eric (1988b). Op. cit., p. 17.

${ }^{16}$ Segundo Hebe Mattos a ausência de sobrenome era uma característica dos escravos. Mattos, Hebe Maria (1998). Das cores do silêncio: os significados da liberdade no Sudeste escravista, Brasil século XIX, Rio de Janeiro: Nova Fronteira, p. 294.
} 
envolvidas não possuíam sobrenome, mas destes apenas em 42 apareceu a menção à cor ou a condição das pessoas. Provavelmente, em boa parte desses registros estão vários casais de libertos, ou mães solteiras com seus filhos. A documentação produzida após a abolição quando menciona os egressos do cativeiro os identificam de várias formas. Nos processos crimes, jornais, ações de tutelas, registro civil e religioso de casamento, nascimento/ batismo e óbito entre outros eles são classificados como libertos, pela cor, origem, ex-escravo de fulano, pertenceu a sicrano etc. ${ }^{17}$

Os casamentos em massa, o reconhecimento de filhos pelos libertos após a emancipação tem sido interpretado pelos estudiosos do período como um desejo que eles tinham de que seus arranjos familiares fossem reconhecidos. Essa atitude ainda pode refletir a importância que esses homens e mulheres, recém-saídos do cativeiro, davam a esses laços dos quais boa parte deles foi privada enquanto perdurou o sistema escravista. Foi comum o reconhecimento de filhos no ato do casamento depois do Treze de Maio, o que demonstra a existência de uma ligação entre os envolvidos ainda nos "tempos do cativeiro". Para muitos libertos manterem a família unida, tê-la reconhecida legalmente pela sociedade, sob as benções de Deus e/ ou pelas leis dos homens, poderia ser interpretada por eles como uma maneira de minimizar o estigma social de que eram vítimas, bem como das acusações de que não levavam uma vida direita.

A grande maioria dos libertos saiu da escravidão sem nada de seu, sem terras, sem casas, sem educação. Mas, possivelmente eles lutaram pelo o que entendiam que Ihes pertenciam depois que raiou a liberdade, ou seja, sua família, seus filhos. É bem provável que a única coisa que boa parte dos ex-escravizados possuía quando do fim da escravidão fossem as suas redes familiares que haviam tecido quando ainda estavam sob o jugo do cativeiro. E ao que parece, eles buscaram mantê-las unidas.

Defender a família e a reputação dos membros da mesma também induz a ideia de que os ex-escravos consideravam como seus direitos tais atitudes. Se o bem que a grande maioria dos libertos possuía eram seus familiares, seus parentes, então era necessário defendê-lo. Fernanda Moutinho de Almeida assinala que em alguns processos de lesão corporal que analisou, no período de 1888-1900 no município de Juiz de Fora, a questão da defesa da família foi a causa da instauração do processo. Em um dos casos examinados pela autora o que motivou o conflito foi o fato de alguns indivíduos mexerem

\footnotetext{
17 Almeida, Fernanda Moutinho de (2003). "Libertos, pretos, negros, africanos, pardos e mulatos - a hierarquia das cores no pós-abolição". In "E depois do 13 de maio"? Conflitos e expectativas dos últimos libertos de Juiz de Fora (1888-1900)". Dissertação (Mestrado em História) - Instituto de Ciências Humanas e Filosofia, Universidade Federal Fluminense, Niterói, p. 44-46, 54.
} 
com as mulheres de dois libertos. Segundo o auto do processo os réus teriam falado "que bonitas morenas para nós carregarmos" frase que foi acompanhada de assovios, ao que o amásio de uma delas teria respondido que elas já tinham "dono", tendo então início o conflito $^{18}$.

A importância que a família e o parentesco tinham na vida dos libertos pode ser mensurada por meio de suas decisões de permanecerem no local ou na região em que haviam sido escravos ou partir deixando para trás suas redes sociais. Possivelmente, para muitos libertos, os laços de parentescos instituídos ainda durante a escravidão foi um fator de fixação no local ou na região onde haviam sido mancípios ${ }^{19}$.

A família que emergiu no pós-abolição diferiu da família escrava em alguns aspectos, mormente no que diz respeito à questão ao governar a mesma. Durante a escravidão era o senhor ou o seu administrador que determinava as tarefas, os castigos. Com a decretação da liberdade os homens recém saídos do cativeiro não permitiam mais que tais direitos coubessem a outros, e nem que determinassem os trabalhos que suas mulheres e filhos teriam que executar. A função de sustentar a família de "ganhar o pão" também passou a ser responsabilidade do chefe da família (do pai, da mãe ou de ambos $)^{20}$. Como no tempo da escravidão, provavelmente, a família continuou a representar uma "mão amiga" nos momentos difíceis, a possibilidade de se ter um pedacinho de terra para cultivar. $\mathrm{Na}$ época do cativeiro o senhor podia permitir que o escravo junto com sua família formasse uma pequena roça, no pós-abolição o arrendamento de um lote de terra, os contratos de parceria, a posse de uma nesga de terra tinham na família o seu principal esteio, era mesmo a condição para a constituição de um "projeto camponês". A família continuou sendo uma possibilidade de sobrevivência frente às adversidades, o preconceito. Acredito que os laços familiares e de parentesco foram para os libertos, o que haviam sido para os escravos, um amparo, o meio onde podiam expressar sua cultura, sua crença, e no seio dos quais solidariedades eram tecidas. Considero que as uniões legais ou consensuais; o estabelecimento de vínculos de compadrio, a luta para reaver os filhos tutelados estavam permeadas pela concepção de que a família era um amparo, o princípio para se construir relações de solidariedade e de reciprocidade.

\footnotetext{
${ }^{18}$ Almeida (2003). Op. cit., p. 109-110. A questão da defesa da reputação da família também foi percebida por Sonia Maria de Souza através dos processos crimes. Souza, Sonia Maria de (2003). Terra, família e solidariedade...: estratégias de sobrevivências camponesa no período de transição - Juiz de Fora (18701920). Tese (Doutorado em História) - Instituto de Ciências Humanas e Filosofia, Universidade Federal Fluminense, Niterói, p. 276-277.

${ }^{19}$ Rios; Mattos (2005). Op. cit., p. 188-189, 220-221.

${ }^{20}$ Foner (1988b). Op. cit., p. 16-20.
} 
Ter uma família, estar ligado a outros indivíduos através do parentesco ou por vínculos de amizade, podia ser de fundamental importância nas horas de necessidades. Possivelmente, essas alianças sociais eram um auxílio nos momentos difíceis. $O$ jornal $O$ Pharol no mês de julho de 1890 noticiou a morte de um indigente de "cor preta" de forma seguinte,

"Em uma pequena casa, que se acha em construção próximo a cidade, faleceu ontem, a 1 hora da tarde, vitima de uma lesão cardíaca, um indigente de cor preta, de 40 anos de idade presumíveis.

Na véspera, á noite, o infeliz tinha-se dirigido ao guarda da cadeia, a fim de pedir-Ihe abrigo, que não Ihe foi dado, sendo-Ihe, entretanto, fornecido uma esteira, e um travesseiro para que ele se acomodasse no lugar em que veio a falecer algumas horas depois.

Informado deste fato, o cidadão subdelegado de polícia deu as necessárias providências, afim de que se averiguasse a causa da morte, a que nos referimos, mandando em seguida proceder a inumação do cadáver ${ }^{21 "}$.

É possível supor que esse homem não possuía uma família e nem fizesse parte de uma rede de parentesco e amizade. Se os tivesse, em vez da ajuda de um desconhecido guarda da cadeia, ele poderia ter buscado o auxílio de um parente, de um compadre. Mas será que não estaria a sua família e sua parentela em outro município ou até mesmo em outra província? Seria esse indivíduo um dos milhares de desenraizados pelo tráfico interno, e que no novo cativeiro não havia conseguido firmar laços de amizade com os outros cativos? Não estaria esse homem perambulando de um distrito para o outro em busca de emprego? Infelizmente apenas conjecturas podem ser tecidas.

O certo é que a vida para muitos libertos no pós-abolição não foi nenhum "roseiral florido"22, mas em meio aos espinhos a família e as alianças de parentesco provavelmente proporcionaram companheirismo, auxílio e solidariedade nos momentos de necessidade.

A construção de laços familiares e de parentesco pelos ex-escravos é um indício de que a escravidão não conseguiu transformá-los em seres destituídos de todos os valores. Geralmente, as fontes só nos informam das redes familiares e parentais que foram registradas nos documentos da Igreja Católica e/ ou dos cartórios. Quantas outras uniões existiram e que não foram legalizadas, registradas? No pós-abolição, houve uma febre entre os libertos para formalizarem suas relações familiares, sendo usual no ato do

\footnotetext{
${ }^{21}$ BMMM-SM: O Pharol, sábado 12 de julho de 1890. O título da notícia é "Morte Súbita".

22 BMMM-SM: O Pharol, sábado 19 de maio de 1888.
} 
matrimônio o reconhecimento de filhos que haviam tido "no tempo de solteiros e sem impedimento algum canônico"23. Esses reconhecimentos acenam para 0 fato da existência de várias uniões dentro das escravarias e é provável que muitas delas estivessem inseridas dentro de uma extensa rede de parentelas, mas que não foram descritas pelos documentos oficiais. Se esses cônjuges não tinham nenhum impedimento canônico para a celebração do casamento, outros fatores, dentre eles a interferência dos senhores, impediu que suas uniões fossem reconhecidas legalmente antes de raiar a liberdade. Mesmo uma grande maioria desses arranjos não tendo sido formalizados, é possível aos estudiosos mensurar o peso e a importância da família e do parentesco para os escravos e libertos através das uniões que foram legalizadas pelas bênçãos da Igreja e pelas leis dos homens.

Examinei as relações matrimoniais dos libertos do município de Juiz de Fora no período compreendido entre o pós 13 de maio de 1888 até o ano de 1900. A documentação utilizada nessa análise foram os registros paroquiais e civis de casamento. $\mathrm{Na}$ documentação consultada foram coletados 304 registros de casamentos envolvendo libertos. $\mathrm{Na}$ análise desses registros, pude apurar que a cor dos envolvidos paulatinamente foi desaparecendo. Isso foi observado tanto na documentação eclesiástica quanto civil. Todavia, a condição de liberto, ex-escravo, pertenceu ao senhor tal, ex-ingênuo etc., foi mais constante que a cor nos anos logo após a abolição nas fontes por mim pesquisadas. Mas mesmo esses adjetivos foram se tornando escassos à medida que os anos passavam. Primeiro silenciaram a cor, depois a condição. $\mathrm{O}$ "sumiço da cor" foi observado por Hebe Mattos em seu estudo sobre o sudeste escravista na documentação produzida no Brasil nos anos finais do escravismo. Para a autora, esse sumiço da cor não está relacionado necessariamente com a questão do branqueamento, mas provavelmente com o fato de que a liberdade não era mais uma prerrogativa dos brancos, uma vez que cada vez mais aumentava o número de negros e mestiços no seio da população livre ${ }^{24}$.

Com relação aos registros civis de nascimento, casamento e óbito instituídos no Brasil em 1888, a descrição da cor dos envolvidos era legalmente obrigatória nessa documentação. $^{25}$ Entretanto, essa determinação nem sempre foi cumprida pelos escrivães dos cartórios. Nos registros civis de casamento da freguesia de São Francisco de Paula, a cor dos nubentes não foi anotada em nenhum dos matrimônios, apenas a

\footnotetext{
${ }^{23}$ CM-AAJF: Livro de Casamento (Chapéu D' Uvas, 1871-1888), fl. 87v, data: 06/12/1888.

${ }^{24}$ Mattos (1998). Op. cit., p. 99.

${ }^{25}$ Rios; Mattos (2004). Op. cit., p. 176.
} 
origem. A origem dos pais dos noivos, quando existiam, também foi registrada. A anotação da origem dos noivos e de seus pais só se deu nos anos de 1889 e 1890, nos demais anos analisados para este trabalho (1895 e 1900) não foi possível identificar mais os libertos nessa documentação, uma vez que a cor, condição (liberto, ex-escravo) e origem deixaram de ser mencionadas.

Como a literatura sobre o pós-abolição na sociedade brasileira tem salientado, no ano de 1888 e de 1889 ocorreu uma corrida pelos libertos para legalizarem suas relações familiares. Essa busca por formalizar suas uniões, segundo as leis da igreja e da nação, é um indício de que eles desejavam que suas uniões fossem reconhecidas pela sociedade, bem como uma tentativa de se construir uma imagem positiva de suas pessoas e de seus familiares. Esse padrão também foi observado para o município de Juiz de Fora. $\mathrm{Na}$ documentação religiosa e civil dos anos de 1888 e 1889, o número de libertos foi bastante expressivo. Nos anos posteriores, ocorreu uma diminuição de registros em que os libertos estão presentes. Entretanto, essa diminuição dos ex-escravos na documentação pode estar relacionada com o fato de que gradualmente a cor e a condição foram desaparecendo dos registros, o que impossibilita a identificação dos mesmos. É provável que em muitos dos assentos em que a cor e a condição não foram mencionadas, estejam os libertos ou seus descendentes. Paulatinamente, os traços da escravidão foram deixando de ser registrados na documentação. Dos 304 registros de matrimônios analisados envolvendo a população liberta e seus descendentes, 141 (46,38\%) ocorreram nos anos de 1888 e 1889. O ano de 1893 foge um pouco ao padrão, pois nesse ano foram realizados na Matriz de Santo Antônio de Juiz de Fora 79 (25,98\%) casamentos envolvendo libertos e seus descendentes, número mais elevado do que a soma dos casamentos realizados na mesma matriz nos anos de 1888 e 1889 que foi de 67 matrimônios. A partir de então ocorre um diminuição significativa. Para o ano de 1900, último de minha análise, foi encontrado apenas um registro entre os 304 em que a cor e a condição dos envolvidos foram mencionadas.

Com relação à cor dos noivos, dos 304 enlaces matrimoniais ela esteve presente em 72 registros e a origem em apenas 49. Nos demais, apenas a observação ex-escravo, liberto, pertenceu ao senhor fulano etc. Em vários registros foi a existência da cor/origem dos pais dos nubentes que me permitiu saber que se tratavam de libertos ou de indivíduos com alguma ligação consanguínea com ex-escravos.

Nos 304 casamentos de libertos realizados nas três freguesias do município de Juiz de Fora analisadas neste trabalho, foi possível identificar o nome dos ex-senhores 
dos nubentes em 206 registros. ${ }^{26}$ Deste total, foi apurado que 86 matrimônios ocorreram entre ex-escravos que haviam pertencido ao mesmo senhor e em 120 entre os que haviam sido de proprietários distintos. Entretanto, é provável que muitos dos exproprietários dos 120 libertos fossem parentes e que a convivência entre os nubentes fosse anterior à abolição. Em vários registros, o sobrenome dos ex-senhores dos nubentes que pertenceram a donos distintos é igual, o que induz a ideia de que os mesmos fossem parentes. A morte de um senhor e a partilha dos bens geralmente causava certa tensão entre a escravaria, pois a possibilidade de separação de grupos familiares nesses momentos era muito grande. Muitas vezes, a partilha dos bens entre os herdeiros era apenas formal, uma vez que na prática o espólio mantinha a sua integridade, seja pelo fato dos herdeiros residirem na mesma propriedade, ou por ser mais vantajosa a todos, a manutenção da unidade sem fracioná-la ${ }^{27}$. Pode-se conjecturar ainda de que esses libertos nos tempos do cativeiro mantiveram contatos com indivíduos das unidades vizinhas, ou seja, eles ultrapassaram as cercas das fazendas. $O$ ir além das fronteiras da propriedade deve ter possibilitado a muitos mancípios estender suas redes de amizade e de parentesco ${ }^{28}$.

O registro de casamento dos libertos Filomeno Augusto de Rezende, preto, 23 anos, filho natural de Castorina [?] dos Santos, preta, ex-escravo do Barão do Retiro ${ }^{29}$ com Marcollina Maria Eugenia da Silva, preta, 21 anos, filha de Eugenia Maria da Silva, ex-escrava de D. Carlota Cândida reforça o argumento de que muitos libertos que pertenceram a senhores diferentes já se conheciam ou tiveram algum contato antes da emancipação em maio de 1888. A ex-proprietária da noiva era sogra do ex-senhor de Filomeno. Esse casal de nubentes reconheceu no ato do matrimônio um filho que haviam

\footnotetext{
${ }^{26}$ O município de Juiz de Fora era composto por cinco freguesias, a de Juiz de Fora (sede), a de Chapéu D'Uvas, a de São Francisco de Paula, a de São José do Rio Preto e a de São Pedro de Alcântara. Para este trabalho foram analisadas a sede do município, São Francisco de Paula e Chapéu D'Uvas.

${ }^{27}$ Cristiany M. Rocha chama a atenção para a necessidade de se acompanhar a trajetória de famílias proprietárias de escravos. Segundo a autora, por meio dessa metodologia é possível observar o impacto das partilhas na vida dos escravos, sendo possível detectar que algumas vezes a divisão dos bens era apenas formal, pois na prática a integridade dos bens era mantida. Rocha, Cristiany Miranda (2004). "A família escrava observada no interior de fazendas em Campinas no século XIX". In Histórias de famílias escravas: Campinas, século XIX, Campinas (SP): Ed. da UNICAMP, p. 107-108.

${ }^{28}$ Segundo Stuart Schwartz a política senhorial de circunscrição e isolamentos dos escravos dentro das propriedades não foi muito eficaz. Os cativos de unidades distintas conseguiram manter contatos entre si. Schwartz, Stuart B (1988). "A família escrava e as limitações da escravidão": In Segredos internos: engenhos e escravos na sociedade colonial, 1550-1835, São Paulo: Companhia das letras, p. 313-314.

${ }_{29}$ Geraldo Augusto de Rezende recebeu o título de Barão do Retiro por decreto imperial de 11 de agosto de 1887. Ele foi casado com Maria Carlota de Rezende (Baronesa do Retiro). O Barão de Juiz de Fora (José Ribeiro de Rezende) foi padrasto do Barão do Retiro. Bastos, Wilson de Lima (1987). "Do caminho Novo dos campos gerais à estrada de rodagem União e Indústria e Estrada de Ferro D. Pedro II". In Bastos, Wilson de Lima et. al. História econômica de Juiz de Fora: subsídios, Instituto Histórico e Geográfico de Juiz de Fora. p. 26.
} 
tido "no tempo de solteiros e sem impedimento algum para se casarem" por nome Generoso, de 5 anos de idade ${ }^{30}$.

Os contatos de vizinhança e amizade como já foram salientados eram importantes para se ter acesso ao casamento, uma vez que era mais fácil encontrar um parceiro e com ele se casar nos lugares onde os indivíduos haviam permanecido e criado laços. ${ }^{31}$ Em minha investigação, nos 304 registros de casamentos de libertos detectei 136 em que a naturalidade dos noivos foi anotada. Desses 136 registros, em 84 veio anotado de onde os nubentes eram naturais e onde residiam. Dos 84 registros, em 29 consta que os noivos eram naturais de freguesias, cidades ou províncias diferentes, mas na época do matrimônio residia na mesma região.

Dos 84 casamentos em que a naturalidade e o local de residência dos contraentes foram assinalados, em 55 (65\%) há a informação de que eles eram "da mesma freguesia" ou "residentes nesta freguesia". Pelos dados acima apresentados percebe-se que os casais que moravam ou eram da mesma freguesia contraíram mais matrimônios do que os provenientes de regiões diferentes ${ }^{32}$. Esse padrão também foi observado por Sonia M. de Souza em seu estudo sobre a população camponesa do município de Juiz de Fora (1870-1920). Segundo a autora, havia uma tendência a "endogamia geográfica" nos casamentos. No caso de noivos "forasteiros", estes geralmente passavam a residir na localidade da noiva ou buscava estreitar laços de parentesco com os moradores da paróquia da mesma, através de vínculos de compadrio ${ }^{33}$.

Os padres e escrivães não foram tão detalhistas nos registros de casamentos dos libertos do município de Juiz de Fora. Dados como a idade, a cor, a origem, a naturalidade e o local de residência são parcamente registrados. O mesmo ocorreu com a profissão dos nubentes. Dos 304 matrimônios de minha análise apenas em 19 apareceu a profissão dos noivos. Deste total, 18 registros foram coletados nos livros de casamento

${ }^{30}$ CM-AAJF: Livro de casamento da Matriz de Chapéu D'Uvas (27/01/1868-13/04/1902), fl. 18v, data: 19/01/1889.

${ }^{31}$ Faria, Sheila de Castro (1998). A colônia em movimento: fortuna e família no cotidiano colonial, Rio de Janeiro: Nova Fronteira, p. 150.

${ }^{32}$ Como já ressaltei foram 136 registros em que a naturalidade ou local de residência dos noivos foram registrados. Entretanto, em 52 apenas a naturalidade foi registrada (de um ou ambos os noivos), não sendo feita referência ao local de residência. Acredito, porém, que os nubentes que não tiveram o local da moradia registrado fossem moradores da freguesia onde o casamento estava sendo realizado, mas na falta de tal observação, preferi não incluir esses casamentos entre os que tiveram a naturalidade e o local de moradia assinalado. Alguns dos locais de naturalidade dos noivos registrados nos livros de casamentos das três freguesias em estudo foram: Pernambuco, Bahia, Ceará, Santa Catarina, Rio de Janeiro, Niterói, Paraíba do Sul, Barra Mansa, Sapucaia, Mateus Leme, Mariana, São João Del Rei, Barra do Ouro Fino, Uberaba, Bagagem, Minas Nova, Pouso Alto de Minas, Sete Lagoas, Formigas, Santo Antonio do Aventureiro, Santo Antônio de Salinas, Oliveira, Tamanduá, Passatempo da Oliveira, Piedade das Gerais, Barros, Conceição etc.

${ }^{33}$ Souza (2003). Op. cit., p. 257-258. 
civil do distrito de São Francisco de Paula, e apenas um nos registros do distrito de Chapéu D'Uvas. Geralmente, era a profissão do noivo que era anotada e não a da noiva, estas tiveram sua profissão declarada em apenas três registros, como sendo roceiras. Dessas três noivas roceiras, duas casaram com noivos roceiros e uma com noivo lavrador. Nos demais registros, a profissão dos noivos foi a de lavrador e a ocupação da noiva não foi declarada.

Segundo Ana Lugão Rios, em seu estudo sobre as relações familiares entre a população afrodescendente em Paraíba do Sul (1872-1920), o termo lavrador geralmente era utilizado no caso de pessoas que estavam "encarregadas de algum empreendimento agrícola próprio, em terras próprias ou alheias" ${ }^{34}$ A autora ainda argumenta que a situação de lavrador e jornaleiro pode ter possibilitado que alguns grupos familiares continuassem a viver juntos, "se formassem, regularizassem ou aspirassem regularizar suas vidas". ${ }^{35}$ Acredito que essas considerações possam ser aplicadas aos noivos de minha análise. Provavelmente, esses libertos que tiveram sua ocupação declarada conseguiram ter acesso a uma porção de terras na condição de agregados, contratos de parceria, arrendatários, ou até mesmo como proprietários. Sonia M. de Souza, em seu trabalho sobre as unidades camponesas do município de Juiz de Fora (1870-1920), procurou demonstrar as múltiplas formas que os homens livres pobres e os libertos tinham de ter acesso a uma nesga de terra própria ou alheia. Segundo a autora, esse acesso podia darse via contratos de pareceria, arrendamento, legados, através da compra etc. ${ }^{36}$.

Com relação às mulheres, apenas três, como já assinalei anteriormente, tiveram a sua profissão declarada, todas como roceiras. Nos demais registros não houve tal anotação. Pode-se conjecturar que apenas a profissão do noivo tenha sido declarada pelos contraentes no momento do casamento. Como a literatura sobre o processo emancipacionista nas Américas tem destacado, houve uma tendência entre os libertos em retirar as mulheres e crianças do serviço do eito. Essa atitude, geralmente, foi passageira, pois o estabelecimento de contratos de meação, os arrendamentos, fez com que o trabalho de todos os membros da família se tornasse indispensável ${ }^{37}$. Creio que as noivas em que o futuro esposo teve a ocupação registrada também desempenhassem atividades relacionadas com a terra. Possivelmente, devido ao fato dos noivos serem responsáveis

\footnotetext{
34 Rios, Ana Maria Lugão (1990). Família e transição (famílias negras em Paraíba do Sul, 1872-1920). Dissertação (Mestrado em História) - Instituto de Ciências Humanas e Filosofia, Universidade Federal Fluminense, Niterói, p. 82.

${ }^{35} \mathrm{lbidem}$, p. 83.

${ }^{36}$ Souza (2003). Op. cit. Ver, principalmente, os capítulos 2 e 4.

${ }^{37}$ Foner (1988a). Op. cit., p. 41/ 1988b, p. 18-19.
} 
por algum empreendimento agrícola próprio, a anotação da ocupação da futura esposa não tenha sido necessária. Sonia Souza, na análise de processos criminais, observou que entre a população camponesa do município de Juiz de Fora, as mulheres não ficavam restritas apenas às atividades domésticas, sendo que também trabalhavam nas lavouras $^{38}$. Ana Lugão também observou nos registros de nascimento de Paraíba do Sul (1872-1920) que as "mulheres negras" casadas não tinham sua profissão declarada. Para a autora, essas mulheres provavelmente auxiliavam seus cônjuges nas atividades agrícolas, mas a documentação lhes dispensou um tratamento igual ao que era dado as "mulheres brancas" casadas 39 .

Como tem sido salientado pela historiografia sobre o pós-abolição, a aquisição de um pedaço de terra era bastante almejada pelos libertos. A sua posse significava a possibilidade de ter mais autonomia, o controle sobre seu tempo, o ritmo de trabalho etc. E a família tinha vital importância para a concretização de tal anseio. Como no período escravista, no pós-abolição a família continuou a representar uma possibilidade de se ter acesso a uma parte de terras e mais, tornou-se um meio de manter a sobrevivência no mundo da liberdade. Tanto para os ex-escravos do meio rural como para os da área urbana, a família, provavelmente, desempenhou um papel de fundamental importância para a sobrevivência dos recém-egressos do cativeiro. Os recursos obtidos pelos libertos em suas atividades era um meio para a manutenção do grupo familiar. Segundo George Reid Andrews, o serviço doméstico de muitas mulheres foi um "salva-vidas" para a população negra ${ }^{40}$. Para os ex-escravos, a possibilidade de empregos nas áreas urbanas não deveria ser muito grande tendo, entretanto, as mulheres uma relativa vantagem em comparação aos homens, uma vez que podiam empregar-se no serviço doméstico.

Além da família representar um meio de sobrevivência, o apego a esses laços pelos libertos também é apontado por outros estudiosos das sociedades emancipacionista da América. Eric Foner ressalta que os libertos do sul dos Estados Unidos colocaram grande empenho em oficializar suas uniões. ${ }^{41}$ Essa atitude também foi percebida nas análises da sociedade brasileira pós 13 de maio de 1888. Como os estudos têm apontado, o ano da abolição no Brasil (1888) e o ano de 1889 são preciosos para os pesquisadores do pós-emancipação. Esse é o período de implantação dos registros civis de nascimento, casamento e óbito. No primeiro momento desses registros, uma gama

\footnotetext{
${ }^{38}$ Souza (2003). Op. cit., p. 253-254.

${ }^{39}$ Rios (1990). Op. cit., p. 85

${ }^{40}$ Andrews, George Reid (1998). Negros e brancos em São Paulo, (1888-1988), Bauru (SP): EDUSC, p. 116.

${ }^{41}$ Foner (1988b). Op. cit., p. 16-17.
} 
variada de informações foi anotada pelos escrivães e que são extremamente valiosas para os pesquisadores desse período. Um desses dados valiosos para o exame do pósabolição são os reconhecimentos de filhos pelos libertos no ato do matrimônio.

$\mathrm{Na}$ coleta que empreendi nos registros eclesiásticos e civis de casamentos nas três freguesias do município cafeicultor de Juiz de Fora em estudo neste trabalho, foram encontrados apenas sete registros em que os nubentes reconheceram filhos que haviam tidos no tempo de solteiros, e em outros dois está anotado que o noivo foi legitimado pelo casamento de seus pais. Abaixo transcrevo um desses registros.

"Certifico em fé de meu cargo que hoje 11 de janeiro de 1890, pelas 11 horas e meia do dia, em meu Oratório, casaram-se os contraentes desta freguesia de cor preta, depois de apregoadas as três vezes canônicas, Albino Gabriel de Souza de 40 anos, filho legitimado por matrimônio subseqüente de Gabriel Antonio de Souza e de Paulina Maria de Jesus, foi de Luiz Calisto Mendes e Marciana Generosa de Jesus, de 25 anos, filha natural de Generosa Januária de Campos, foi de Marcelino Esteves Pereira. Foi em minha presença e das $t^{t^{2}}$ Francisco Esteves Pereira, Joaquim Esteves Pereira e $M^{a}$ Augusta de Campos, sua mulher. (grifos meus)

Chapéu D'Uvas 11 de Janeiro de 1890.

Vigário Vicente Ferreira Passos ${ }^{42}$ ".

Por esse registro de casamento pode-se perceber que os pais do noivo tinham uma relação duradoura, estavam juntos há pelo menos 40 anos (idade do noivo). É provável que tivessem outros filhos e que estivessem ligados a outros indivíduos através do parentesco ritual estabelecido através de relações de compadrio durante o período escravista.

O casal de libertos Joaquim Ferreira Meirelles e Vicência também reconheceu durante o matrimônio que se realizou no dia 22 de janeiro de 1890 no Oratório de Chapéu D'Uvas cinco filhos que tiveram nos "tempos do cativeiro", mas não há o nome destes. Joaquim era africano e contava com 60 anos de idade quando se casou com Vicência, preta de 61 anos, filha de Maria Cabinda. O registro informa que os noivos foram escravos de José Ferreira Meirelles, mas não diz sobre a mãe da noiva, embora acredite que a mesma também tenha pertencido a este senhor. ${ }^{43}$ Nos registros de batismo não foi

\footnotetext{
${ }^{42}$ AHCJF: Fundo Cartório de Paula Lima, Série: Documentos relativos a casamentos -27 Certificados de Casamentos (1879-1944). Registro no 86.

${ }^{43}$ AHCJF: Fundo Cartório de Paula Lima, Série: Documentos relativos a casamentos -27 Certificados de Casamentos (1879-1944). Registro oㅜ 87. Com relação ao noivo não há referência de sua etnia, apenas que era africano.
} 
possível identificar nenhum dos filhos deste casal. Uma das possibilidades plausíveis para a total ausência destes se deve ao fato de que trabalhei por amostragem. Os batizados podem ter ocorrido nos anos que não foram analisados por mim, pode-se ainda conjecturar que a ex-escrava Vicência poderia ter pertencido a outro senhor antes de tornar-se propriedade de José Ferreira Meirelles. Nos assentos de batismo há várias cativas com o nome de Vicência, mas nenhuma como sendo escrava do dito senhor.

O que teria levado esses libertos a se casarem, já que estavam com uma idade mais avançada? Pode-se especular que fosse uma maneira de afirmarem a sua liberdade, uma vez que haviam tido cinco filhos durante o período em que foram escravos e não puderam, provavelmente, oficializar essa união devido à interferência senhorial. Segundo Sheila Faria, na sociedade colonial brasileira o casamento era buscado como uma maneira para se conseguir uma "estabilidade familiar" e também o "respeito social, fundamental, no caso dos homens brancos de qualquer crença, e estratégico, no caso de escravos, forros e mestiços" ${ }^{\prime 4}$. O casar segundo as leis de Deus e dos homens poderia representar para esses libertos de minha amostra uma maneira de se conseguir o respeito social para si e seus familiares. Como já foi ressaltado os casamentos em massa de ex-escravos no pós 13 de maio são um sinal de que eles desejavam que seus laços familiares fossem reconhecidos e respeitados pela sociedade, bem como de que os mesmos eram valorizados por eles.

A noiva Vicência filha de uma africana Cabinda, conviveu consensualmente durante alguns anos com um africano (a fonte não informa de que grupo étnico era o noivo) que veio a tornar-se seu marido no pós-emancipação. Muitas das tradições e costumes africanos devem ter sido transmitidas aos seus filhos e netos. Possivelmente, 0 casal de noivos já era avô e juntamente com seus filhos deviam estar ligados a vários outros indivíduos da sociedade onde residiam através dos laços de parentescos instituídos através do batismo.

A documentação também nos informa da legitimação de mais 12 filhos havidos por seis casais de noivos no tempo em que eram solteiros. A criança mais nova tinha 3 meses e a mais velha 10 anos mais ou menos. Todos esses reconhecimentos deram-se nos anos de 1888, 1889 e 1890. Tais observações só foram encontradas nos registros da freguesia de Chapéu D'Uvas ${ }^{45}$. Nos registros das outras duas freguesias analisadas não houve tais anotações. Entretanto, presumo que muitos nubentes da Matriz de Santo

\footnotetext{
${ }^{44}$ Faria (1998). Op. cit., p. 304.

${ }^{45}$ CM-AAJF: Livros de Casamentos da freguesia de Chapéu D"uvas (1870-1900); AHCJF: Fundo: Cartório Paula Lima, Série: Documentos relativos a casamentos - 27 Certificados de Casamentos (1879-1944).
} 
Antônio de Juiz de Fora e da de São Francisco de Paula também tiveram filhos nos tempos de solteiros e do cativeiro. Se os tiveram, estes não foram anotados nos registros de casamentos por não terem sidos citados pelos pais ou pelo fato dos párocos e escrivães não terem registrado as informações fornecidas pelos noivos.

Apesar de ser uma pequena amostra, estas legitimações por "subsequente matrimônio" evidencia que a constituição de família, era valorizada pelos homens e mulheres que viveram sob o jugo do cativeiro.

$\mathrm{Na}$ análise dos registros de batismos e de nascimentos pode-se observar, também, a importância atribuída pelos escravos e libertos aos seus laços de família e de parentesco. O parentesco instituído através do rito católico do batismo possibilitava aos indivíduos a ampliação de suas relações sociais. O batismo além do seu caráter religioso e sagrado também comportava um aspecto funcional, ou seja, estabelecia vínculos de solidariedade entre os envolvidos, pelo menos era o que se esperava ao se estabelecer essa relação de parentesco ritual.

Maria de Lourdes Bandeira no estudo antropológico sobre a comunidade negra de Vila Bela (Vale do Guaporé - Mato Grosso) apurou que o compadrio tinha grande importância entre seus membros. Por intermédio dele se criava "vínculos formais de parentesco" ${ }^{46}$ que eram perpassados pelos princípios de solidariedade e de reciprocidade. Segundo os depoimentos dos moradores, os parentes auxiliavam os filhos das mulheres solteiras e/ ou viúvas com dificuldades financeiras, sendo que muitos afilhados foram criados pelos padrinhos ou pelas madrinhas. Os pais viúvos também podiam contar com o apoio das madrinhas na criação das crianças $^{47}$.

Segundo Ana Lugão Rios, nos registros de nascimento de Paraíba do Sul (18721920) os ex-escravos procuraram após a emancipação estreitar seus laços de solidariedade através do compadrio com os seus iguais, em vez de reforçar as "relações clientelistas e paternalistas" com indivíduos de posição social superior. ${ }^{48}$ A autora assinala que o cruzamento dos dados sobre a profissão dos pais e dos padrinhos é mais um indício de que os recém-egressos do cativeiro privilegiaram estabelecer vínculos de compadresco com pessoas do mesmo nível social. Nos registros que analisou, 150 pais foram declarados como lavradores, deste total em 134 a profissão dos padrinhos também veio registrada. Dos 134 padrinhos em que a atividade foi mencionada $73 \%$ eram

\footnotetext{
${ }^{46}$ Bandeira, Maria de Lourdes (1988). "Segundo ato: Vila Bela dos Pretos". In Território negro em espaço branco: um estudo antropológico de Vila Bela, São Paulo: Brasiliense, p. 154.

47 Ibidem, p. 151, 154-155.

${ }^{48}$ Rios (1990). Op. cit., p. 87.
} 
lavradores. De acordo com Ana Lugão, dos padrinhos em que foi possível identificar a ocupação profissional, $88 \%$ eram de posição social igual ou semelhante a dos pais dos neófitos pretos e pardos, com uma predileção pelos que exerciam a mesma atividade profissional dos genitores da criança ${ }^{49}$.

$\mathrm{Na}$ análise dos registros de batismo e de nascimento de crianças filhas de libertos das freguesias em estudo neste trabalho, não foi possível identificar a profissão dos padrinhos devido ao fato de não terem sido registrada ${ }^{50}$. Os assentos de nascimento contêm mais informações que os de batismo. Neles foram anotados os nomes das crianças, dos pais da criança, a profissão do pai, o nome dos avós, mas infelizmente não foi feita a indicação de quem foram os padrinhos ou seria os padrinhos das crianças.

Coletei 232 registros de crianças sendo batizadas ou registradas, mas deste total em apenas 57 assentos a ocupação dos pais da criança foi declarada, sendo que cinquenta e dois foram descritos como lavradores e cinco como roceiros. Nenhuma das mães teve a profissão declarada.

Da mesma forma que a profissão dos padrinhos não foi declarada nos registros de batismo e de casamento, a provável existência de laços de parentesco entre muitos deles também não foi mencionada. A identificação desses laços também foi dificultada devido a grande presença de homônimos, aos nomes religiosos entre as mulheres, a falta de sobrenome entre os envolvidos e a constante mudança de sobrenome dos indivíduos. Foram pesquisados 232 assentos de batismo e nascimento de crianças filhas de afrodescendentes. Deste total, em apenas 3 (1,29\%) foi possível perceber uma ligação de parentesco entre os pais do batizando e os padrinhos.

Dos 232 registros de batismo e nascimento em apenas $42(18,10 \%)$ foi possível identificar um passado escravos entre os pais espirituais. Tal constatação se deu através da menção da cor/ origem ou da declaração de que eram libertos ou ex-escravos. Ao todo foram 24 (10,34\%) madrinhas e 18 (7,76\%) padrinhos em que tais informações aparecem. $^{51}$ Com relação aos padrinhos livres, somente em 22 assentos deu para perceber a sua presença. Como já salientei anteriormente, a grande incidência de homônimos, os sobrenomes religiosos comuns entre as mulheres livres e libertas, a constante troca de sobrenomes dificulta identificar se os indivíduos com sobrenomes são

\footnotetext{
${ }^{49}$ lbidem, p. 88.

${ }^{50}$ Apenas dois registros civis contêm informação sobre a profissão dos padrinhos.

51 CM-AAJF e CMJF: livros de batismos (1870-1900). Dos 216 registros de batismo em apenas 5 aparece a origem dos padrinhos ( 3 africanos e 1 crioulo) e com relação as madrinhas somente uma é descrita como crioula. A cor dos padrinhos é informada em apenas um registro (preto) e a da madrinha em três (1 parda e 2 pretas).
} 
livres ou libertos. Observei do exame dessa documentação um número expressivo de pais espirituais sem sobrenome. Esses dados, à primeira vista indicam a existência de um passado escravo, pelo fato de que a adoção de sobrenome não era algo muito comum entre a população escrava do Brasil, mas a falta de dados mais concretos me induziu a não classificá-los entre os indivíduos egressos do cativeiro. Creio, entretanto, que boa parte dos pais espirituais sem sobrenome possuía um passado escravo.

É provável que uma parcela substancial dos libertos do município de Juiz de Fora, como os escravos no tempo da escravidão, tenham escolhido para apadrinharem seus filhos pessoas de condição social igual ou semelhante a que possuíam. Tal atitude se justificaria pelo desejo de se afastarem de toda a interferência de ex-senhores em suas relações pessoais. A aliança com pessoas do mesmo estrato social poderia ser visualizada pelos libertos como uma maneira de reforçar os laços de amizade e de vizinhança existentes. Através do compadrio, os ex-escravos podiam aumentar suas relações de solidariedade com pessoas da própria família ou com outros indivíduos que compartilhavam da mesma condição social e de vida. Robert Slenes ressalta que muitos escravos buscaram o caminho do "favor" senhorial na esperança de conseguir a alforria. Mas esses mancípios não deveriam desprezar a "amizade" de seus parceiros, pois a qualquer momento a relação com o senhor poderia tornar-se tensa por algum motivo sério ou banal e eles se veriam sem apoio se os laços de amizade com os seus companheiros de cativeiro tivessem sido cortados quando ainda encontravam-se nas "graças" do senhor $^{52}$. Presumivelmente, muitos libertos consideraram mais acertado manter e ampliar os laços com seus iguais do que com os homens bons da região, uma vez que estes arranjos poderiam tornar-se problemáticos no futuro ou não serem caracterizados pela solidariedade entre compadres. Como nos tempos da escravidão, era importante para os libertos manterem os laços com os seus iguais.

\section{Fontes}

\section{Manuscritas}

CATEDRAL METROPOLITANA DE JUIZ DE FORA

- Registros paroquiais de Batismos e Casamentos

CÚRIA METROPOLITANA - ARQUIVO ARQUIDIOCESANO DE JUIZ DE FORA

- Registros paroquiais de Batismos e Casamentos

\footnotetext{
52 Slenes Robert W. (1997). "Senhores e subalternos no Oeste paulista". In Novais, Fernando A. (coord.). Alencastro, Luiz Felipe de. (org.). História da vida privada no Brasil: Império, São Paulo: Companhia das Letras, p. 279-280.
} 


\section{ARQUIVO HISTÓRICO DA CIDADE DE JUIZ DE FORA}

- Fundo Cartório de Chapéu D’Uvas/ Paula Lima

- Documentação Cível

- Registros de Casamentos e Nascimento

- Fundo Cartório de São Francisco de Paula

- Documentação Cível

- Livros de Registros de Nascimento

- Livros de Registros de Casamentos

\section{Impressas}

BIBLIOTECA MUNICIPAL MURILO MENDES - SETOR DE MEMÓRIA

- Jornal O Pharol

\section{Referências Bibliográficas}

Almeida, Fernanda Moutinho de (2003). "E depois do 13 de Maio?" conflitos e expectativas dos últimos libertos de Juiz de Fora (1888-1900). Dissertação (Mestrado em História) - Instituto de Ciências Humanas e Filosofia, Universidade Federal Fluminense, Niterói.

Andrews, George Reid (1998). Negros e brancos em São Paulo, (1888-1988). Tradução Magda Lopes, Bauru (SP): EDUSC.

Bandeira, Maria de Lourdes (1988). "Segundo ato: Vila Bela dos Pretos". In Território negro em espaço branco: um estudo antropológico de Vila Bela, São Paulo: Brasiliense.

Bastos, Wilson de Lima (1987). "Do Caminho Novo dos campos gerais à estrada de rodagem União e Indústria e Estrada de Ferro D. Pedro II". In Bastos, Wilson de Lima et. al. História econômica de Juiz de Fora: subsídios, Instituto Histórico e Geográfico de Juiz de Fora.

Faria, Sheila S. de Castro (1998). A colônia em movimento: fortuna e família no cotidiano colonial, Rio de Janeiro: Nova Fronteira.

Foner, Eric (1988a). Nada além da liberdade: a emancipação e seu legado, Rio de Janeiro: Paz e Terra; Brasília: CNPq.

Foner, Eric. (1988b). "O significado da liberdade". In Lara, Silvia Hunold (org.). (1988). Escravidão. Revista Brasileira de História, São Paulo: ANPUH/ Marco Zero, vol. 8, nº 16, mar/ag. 
Holt, Thomas C. "A essência do contrato: a articulação entre raça, gênero sexual e economia política no programa britânico de emancipação, 1838-1866". In Cooper, Frederick et. all. (2005). Além da Escravidão: investigação sobre raça, trabalho e cidadania em sociedades pós-emancipação, Rio de Janeiro: Civilização Brasileira.

Mattos, Hebe Maria (1998). Das cores do silêncio: os significados da liberdade no Sudeste escravista, Brasil século XIX, Rio de Janeiro: Nova Fronteira.

Rios, Ana Lugão. e Mattos, Hebe (2005). Memórias do cativeiro: família, trabalho, e cidadania no pós-emancipação, Rio de Janeiro: Civilização Brasileira.

Rios, Ana Lugão. e Mattos, Hebe (2004). "O pós-abolição com problema histórico: balanços e perspectivas". In Topoi, v. 5, n. 8, jan.-jun, p. 170-198.

www.ppghis.ifcs.ufri.br/media/topoi8a5.pdf

Rios, Ana Maria Lugão (1990). Família e transição: famílias negras em Paraíba do Sul (1872-1920). Dissertação (Mestrado em História) - Instituto de Ciências Humanas e Filosofia, Universidade Federal Fluminense, Niterói.

Rocha, Cristiany Miranda (2004). Histórias de famílias escravas: Campinas, século XIX, Campinas (SP): Ed. da UNICAMP.

Schwartz, Stuart B. (1988). Segredos internos: engenhos e escravos na sociedade colonial, 1550-1835, São Paulo: Companhia das Letras.

Slenes, Robert W. (1997). "Senhores e subalternos no Oeste paulista". In Novais, Fernando A. (coord.). Alencastro, Luiz Felipe de. (org.). História da vida privada no Brasil: Império, São Paulo: Companhia das Letras.

Souza, Sonia Maria de (2003). Terra, família e solidariedade...: estratégias de sobrevivência camponesa no período de transição - Juiz de Fora (1870-1920). Tese (Doutorado em História) - Instituto de Ciências Humanas e Filosofia, Universidade Federal Fluminense. Niterói.

\section{Recebido para publicação em março de 2012.}

Aprovado para publicação em abril de 2012. 